\title{
Discutindo o ensino de geometria: uma proposta para o ensino dos poliedros regulares ${ }^{1}$
}

Maira Mendias Lauro

Mestre em Educação - Ensino de Ciências e Matemática - USP; Professora na graduação - Uninove. São Paulo - SP [Brasil] maira@uninove.br 


\section{Introdução}

Nosso interesse pelo ensino de geometria resulta da experiência vivenciada nos cursos de aperfeiçoamento ministrados para professores de matemática dos Ensinos Fundamental e Médio da rede estadual e nas disciplinas específicas de geometria e desenho geométrico, ministradas para os alunos ingressantes no curso de licenciatura em matemática da Universidade Nove de Julho. Em ambos os casos, pudemos observar grandes problemas e, que, a cada ano, os alunos vêm apresentando muitas dificuldades em relação aos conceitos geométricos elementares.

Lamentavelmente, nas aulas de geometria, o ensino de desenho geométrico tem sido deixado de lado para dar maior ênfase à observação e à manipulação de objetos materiais nas primeiras séries da escolarização e à sistematização conceitual, formal ou informal, nas últimas séries dos ensinos Fundamental, Médio e Superior. Sendo a geometria trabalhada dessa forma, quase sempre os estudantes recorrem à memorização para enfrentar as dificuldades lógicas apresentadas pelo método axiomático-dedutivo. Não há articulação entre os processos que dizem respeito à "percepção" com os teóricos que se referem à "concepção" e, menos ainda, com os processos de "construção" de materiais que possam ser manipulados e os de "representação" por meio de desenhos de objetos percebidos ou construídos.

A maioria dos professores parece não estabelecer nenhuma articulação entre os processos citados; por isso, sentem-se inseguros para ensinar geometria, pois não se sentem preparados. Dessa forma, os alunos chegam ao curso superior com pouquíssimas noções estabelecidas. Ressalte-se que muitos nunca tiveram contato com os instrumentos de desenho, pois a geometria que lhes foi apresentada não ar- ticulou os quatro aspectos citados, o que, para se tornar um círculo vicioso, faz que o desenho geométrico, gradualmente, desapareça do currículo real das escolas.

Neste artigo, pretendemos apresentar um exemplo de proposta diferenciada para o ensino dos poliedros regulares. As atividades são elaboradas respeitando os atuais Parâmetros Curriculares Nacionais (PCNs), que estabelecem equilíbrio e trânsito entre os quatro processos fundamentais no ensino da geometria. Em primeiro lugar, tratamos de algumas pesquisas que fundamentam a elaboração deste trabalho. A fonte principal norteadora é a dinâmica da construção do conhecimento geométrico (MACHADO, 1990, 2002) que garante que, nesse processo, em vez de uma polarização percepção/concepção, é fundamental a caracterização de quatro aspectos: a percepção, a construção, a representação e a concepção.

\section{0 ensino da geometria}

Os objetos do mundo físico possuem alguma forma e tamanho ou ocupam alguma posição no espaço. Assim, as formas ou padrões geométricos constituem os modelos mais elementares para muitos tipos de fenômenos da nossa vida cotidiana, tais como medir (as dimensões de um apartamento), examinar formas (a forma de um favo de mel, das moléculas de um cristal, das células, de algumas conchas do mar ou das pétalas de uma flor), comparar tamanhos (a água deste copo cabe naquela xícara?), analisar posições (a rua A é perpendicular ou paralela à rua B?), representar e construir (a planta e a maquete de uma casa). A geometria é a ferramenta que o ser humano criou para estudar essas entre outras questões. 
Neste contexto, podemos dizer que o ensino de geometria, de modo geral, é importante para a criação do hábito de ver e compreender as formas e os contornos dos objetos, o que estimula a imaginação e a intuição e desenvolve o raciocínio e a compreensão do espaço.

Todavia, segundo Kaleff e colaboradores (1997), apesar dessa intensa relação entre a geometria e o mundo à nossa volta, pouca atenção tem sido dada a ela nas aulas de matemática.

Nas aulas de geometria nas primeiras séries da escolarização, de modo geral, as atividades propostas envolvem somente a percepção, ou seja, a observação e a manipulação de objetos materiais e a caracterização, por meio de atividades empíricas, das formas mais freqüentes presentes no mundo à nossa volta. Já nas últimas séries dos Ensinos Fundamental, Médio e Superior, as atividades relacionadas com a geometria, são direcionadas à concepção, isto é, à sistematização, ao exercício da lógica, dos elementos conceituais, nos quais predominam as definições formais, o enunciado preciso de propriedades e as proposições e teoremas com suas demonstrações, ou seja, "[...] é como se a Geometria fosse organizada segundo um vetor com origem nas atividades perceptivas e extremidade na sistematização formal." (MACHADO, 2002, p. 53).

A passagem da percepção para a concepção é feita de maneira abrupta: o estágio inicial parece estar voltado a certa infantilização, havendo, em seguida, um rompimento, no qual se busca o conhecimento geométrico por meio do raciocínio lógicodedutivo e pela teorização. Machado (2002, p. 52) baliza essa visão, pois, segundo o autor, "[. . .] para a compreensão da dinâmica do processo de construção do conhecimento geométrico, a polarização entre as atividades perceptivas e a sistematização conceitual parece claramente insatisfatória."
Ainda, para o mesmo autor, é essencial que exista uma articulação entre a percepção e a concepção, estabelecendo caminhos convenientes que permitam um trânsito natural entre ambas, com dupla mão de direção. (MACHADO, 2002, p. 53).

Assim, entendemos que limitar-se à atividades de manipulação de objetos materiais, mesmo nas séries iniciais do ensino, seja insuficiente; e trabalhar apenas com o conceitual, sem relações com objetos materiais, em todos os níveis do ensino, talvez seja ainda pior, daí a importância da articulação entre a percepção e a concepção.

o problema torna-se maior ao constatarmos que, no processo de construção do conhecimento geométrico, outras duas dimensões da dinâmica do processo cognitivo, no caso da geometria - a construção e a representação - para as quais tanto o desenho geométrico quanto a geometria projetiva e a descritiva são fundamentais, praticamente foram banidas da maioria das escolas e dos livros didáticos.

Acreditamos que o uso da régua e do compasso na resolução de problemas geométricos desenvolva o raciocínio lógico-dedutivo, a coordenação motora, além do sentido de organização, limpeza, ordem, capricho, precisão, conservação. Independentemente da área a que possa se dedicar como profissional, o estudante terá elementos fundamentais à sua formação.

Dessa forma, no processo de construção do conhecimento geométrico, não basta o estabelecimento de articulações entre atividades perceptivas, manipulativas e concepções; é fundamental a existência de ênfase em quatro dimensões desse tipo de conhecimento: a percepção, a construção, a representação e a concepção. Em Machado (2002, p. 54), encontramos que,

[...] não obstante o fato de a iniciação em geometria realizar-se por meio da per- 
cepção de formas e de suas propriedades características, através de atividades sensoriais, como a observação e a manipulação de materiais, desde muito cedo tais atividades relacionam-se diretamente com a construção de objetos em sentido físico, através de massas, varetas ou papéis, por exemplo, bem como com a representação de objetos, através de desenhos, onde as propriedades costumam ser parcialmente concretizadas.

Lamentavelmente, constatamos um "esquartejamento" no ensino da geometria, por não haver articulação entre os quatro processos. A conseqüência observada nesse panorama é que, quase sempre, os estudantes recorrem à memorização para enfrentar as dificuldades lógicas apresentadas pelo método axiomático-dedutivo, o que faz que os alunos não compreendam a geometria no sentido de uma construção significativa.

Cabe ao professor, portanto, procurar estratégias de ensino, evitando o tratamento isolado de qualquer uma das quatro faces.

Com relação a esses fatos, Machado (1990, p. 146) afirma que

É tão importante transitar, como uma criança, da percepção à construção, daí à representação e, então, à concepção, quanto o é realizar o percurso do engenheiro ou do arquiteto, que concebe o objeto geométrico antes de representá-lo e construí-lo, e só então torná-lo palpável.

De modo geral, em todos os níveis do ensino, a geometria não deveria ser tratada de forma dilacerada; seu ensino necessita de atividades integrado- ras que articulem os quatro processos descritos da construção do conhecimento geométrico.

\section{Uma proposta para o ensino dos poliedros regulares}

Conforme discutido, no processo de construção do conhecimento geométrico, consideramos fundamental enfatizar as quatro dimensões desse tipo de conhecimento: a percepção, a construção, a representação e a concepção. Nesse contexto, a título de exemplificação, propomos um conjunto de atividades que possibilitem aos alunos e professores estabelecer essas ênfases.

Iniciaremos com atividades empíricas e exploratórias, tendo em vista a percepção, mas tais atividades estarão diretamente relacionadas com a construção de objetos em sentido físico e com a representação de objetos por meio de desenhos, em que suas propriedades e características serão explicitadas, considerando-se o nível de amadurecimento dos alunos. Como sugerem os PCNs (BRASIL, 1998), por meio da intuição e de experiências concretas, os estudantes serão levados a estabelecer conclusões, definindo um percurso que lhes permitam compreender a importância e a necessidade de argumentos para legitimar as conjecturas formuladas.

Escolhemos o tema "poliedros regulares" que permite a exploração de objetos do mundo físico e da natureza, de maneira que se estabeleçam conexões entre a matemática e outras áreas do conhecimento.

É importante ressaltar que o professor tenha em mente os objetivos do trabalho para que alunos estejam dirigindo suas atividades. Dessa forma, uma mesma atividade pode ser proposta a estudantes de diferentes níveis escolares, usando distintas formas 
de exploração das propriedades e das relações matemáticas envolvidas.

\subsection{Poliedros regulares: um caminho investigativo}

Para começar a trabalhar com os poliedros regulares, convém, em primeiro lugar, relembrar com os alunos o conceito de polígono regular. Em seguida, pode-se propor a seguinte questão: Quantos polígonos regulares existem? De modo geral, os alunos respondem a essa indagação sem grandes problemas (existem tantos tipos de polígonos regulares quantos são os números naturais a partir de 3).

Após as características dos polígonos regulares terem sido bem especificadas, podemos definir os poliedros regulares, e a questão natural a ser levantada é: quantos poliedros regulares existem? Geralmente, a resposta a essa questão é análoga a que foi dada para os polígonos regulares: "existem infinitos poliedros regulares”. No entanto, isso não é verdade, e a nossa proposta é que os alunos descubram, por meio de atividades empíricas, que só existem cinco tipos de poliedros regulares.

\section{Atividade I: Triângulos eqüiláteros}

Primeiro, vamos considerar poliedros regulares cujas faces são triângulos eqüiláteros.

O professor pode pedir que os alunos construam, com régua e compasso, seis triângulos eqüiláteros em uma cartolina e recortando-os em seguida.

Começando com três triângulos eqüiláteros, como na figura abaixo à esquerda, e juntando os pontos A e B, podem se formar o primeiro vértice de um poliedro regular. Na seqüência, solicita-se aos alunos que façam a experiência com os triângulos construídos.
Ao completarem os demais vértices de modo que todos sejam idênticos, obtêm o poliedro regular de quatro faces: o "tetraedro regular".

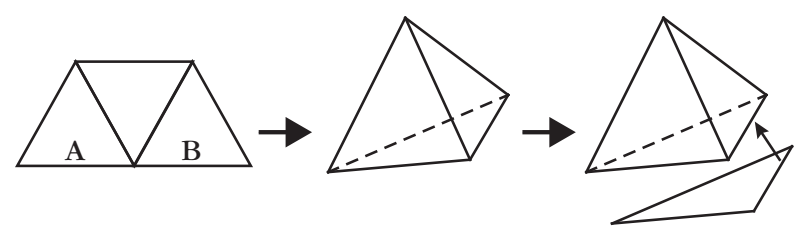

Figura 1: 0 tetraedro regular Fonte: A autora.

Agora, podemos propor outras atividades de construção de um tetraedro regular:

\subsection{Construindo um tetraedro regular com um envelope selado}

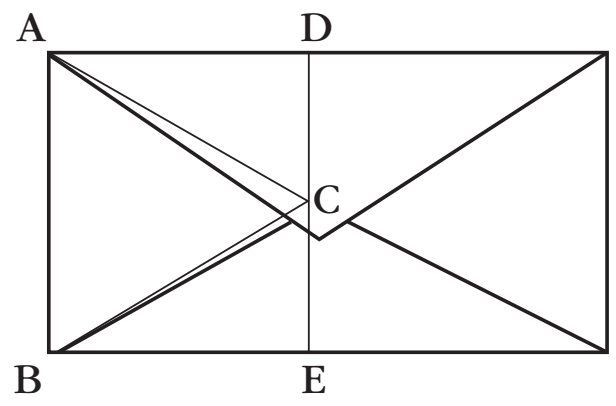

Figura 2: Envelope selado

Fonte: O'Daffer; Clemens, 1976.

a) Construa o ponto $\mathrm{C}$ de modo que o triângulo $\triangle \mathrm{ABC}$ seja eqüilátero;

b) Construa o segmento $\overline{\mathrm{DE}}$ que passa por C e é paralelo a $\overline{\mathrm{AB}}$;

c) Corte ao longo do segmento $\overline{\mathrm{DE}}$;

d) Dobre $\overline{\mathrm{AC}}$ e $\overline{\mathrm{BC}}$ para trás e para frente em ambas as direções; 
e) Encontre o ponto correspondente ao ponto $\mathrm{C}$ no lado oposto do envelope e chame-o de C';

f) Aperte o envelope de modo que os pontos D e E fiquem juntos, e C e C'; separados.

Cole com uma fita adesiva ao longo do segmento CC' e o tetraedro regular estará completo.

\subsection{Construindo um tetraedro regular com tiras de papel (HILTON; PEDERSEN, 1988)}

Para construir o tetraedro, necessita-se de duas tiras de papel, cada formada por cinco triângulos eqüiláteros como ilustrado na Figura 3. Peça que os alunos o construam com régua e compasso.

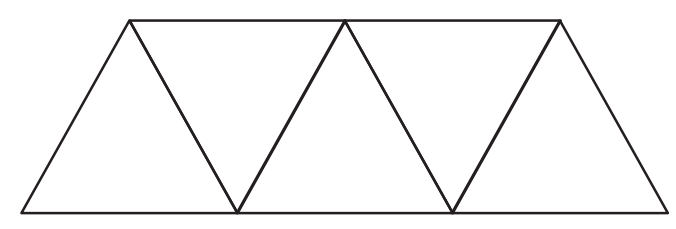

Figura 3: Tira de papel

Fonte: A autora.

Coloque uma tira sobre a outra, exatamente como indicado na Figura 4. Sobreponha os dois triângulos indicados com a letra $\mathrm{X}$ de modo que C' encontre $\mathrm{C}, \mathrm{B}$ ' encontre $\mathrm{B}$ e D' encontre $\mathrm{D}$. Dessa forma, você terá formado um tetraedro com três triângulos ligados em uma de suas arestas. Complete o tetraedro envolvendo a tira restante ao redor de duas de suas faces e, finalmente, coloque o triângulo indicado com a letra $\mathrm{Y}$ dentro da abertura ao longo da aresta BC.

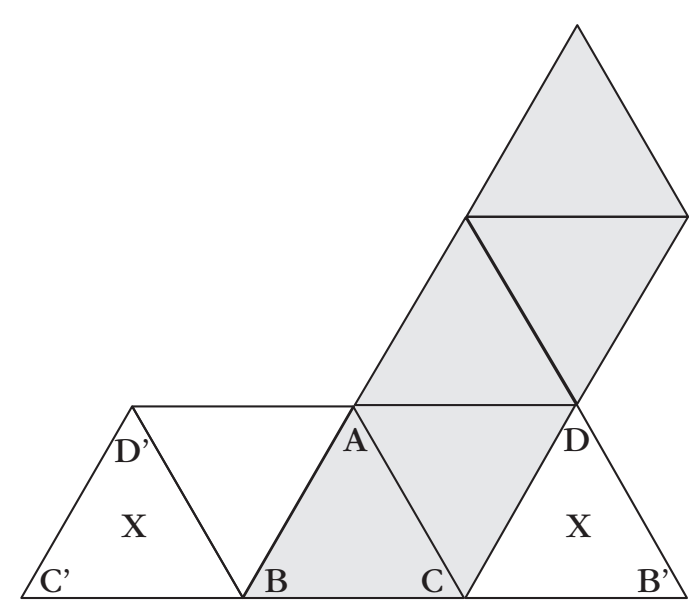

Figura 4: Esquema de montagem do tetraedro regular Fonte: Hilton; Pedersen, 1988.

Pode-se observar que as atividades anteriores, assim como as próximas, permitem explorar, articuladamente, a percepção, a construção, a representação e a concepção.

Vamos agora considerar quatro triângulos eqüiláteros, como mostrado na Figura 5. Juntando os pontos A e B, formamos o primeiro vértice do poliedro regular. Peça para que os alunos façam a experiência com os triângulos inicialmente construídos.

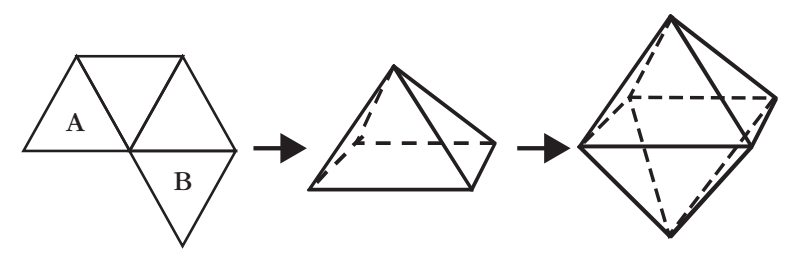

Figura 5: 0 octaedro regular

Fonte: A autora.

Completando os demais vértices de modo que todos sejam formados por quatro triângulos, temos o poliedro regular de oito faces: o "octaedro regular". 


\subsection{Construindo um octaedro regular com tiras de papel (HILTON; PEDERSEN, 1988)}

Para construir o octaedro, necessita-se de quatro tiras de papel, cada formada por sete triângulos eqüiláteros como ilustrado na Figura 6 . Peça que os alunos os construam com régua e compasso.

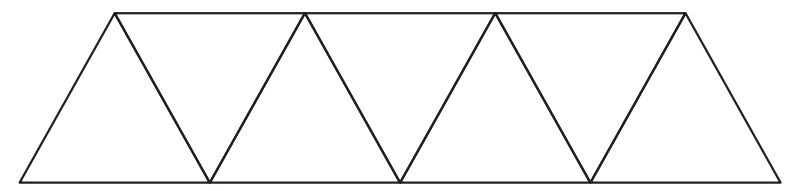

Figura 6: Tira de papel

Fonte: A autora

Comece com um par de tiras sobrepostas como indicado na Figura 7 à esquerda (cole com uma fita adesiva os triângulos sobrepostos indicados, para facilitar o manuseio). Dobre as tiras, colocando o triângulo a embaixo do triângulo $\mathrm{A}_{1}$, o triângulo $\mathrm{a}_{2}$ embaixo do triângulo $\mathrm{A}_{2}$ e o triângulo b em baixo do triângulo B. Cole os triângulos sobrepostos b e B. Assim, serão formadas duas "pirâmides" conforme a figura do centro. Repita esse processo com o segundo par de tiras e coloque-o em cima do primeiro par de tiras trançadas, como mostrado na Figura 7 à direita. Complete o octaedro, seguindo os passos indicados nessa figura. (Note que, após o primeiro passo, você terá formado um octaedro; execute o segundo passo simplesmente juntando a aba ${ }_{1}$ e a face do octaedro; no terceiro passo, você deverá colocar a aba ${ }_{2}$ dentro do modelo).

Considerem-se agora cinco triângulos eqüiláteros, como mostrado na Figura 8 à esquerda. Juntando os pontos A e B, forma-se o primeiro
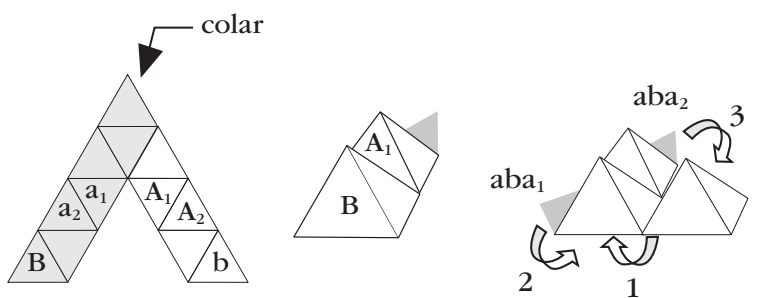

Figura 7: Esquema de montagem do octaedro regular Fonte: Hilton; Pedersen, 1988.

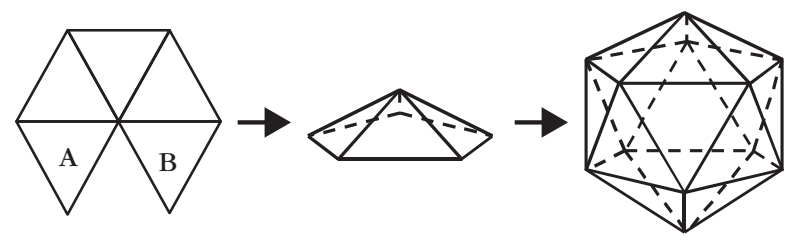

Figura 8: 0 icosaedro regular

Fonte: A autora.

vértice do poliedro regular. Peça que os alunos façam a experiência com os triângulos inicialmente construídos.

Completando os demais vértices de modo que todos sejam formados por cinco triângulos, obtém-se o poliedro regular de 20 faces: o "icosaedro regular".

\subsection{Construindo um icosaedro regular com canudos de plástico unidos por meio de um fio de linha (KALEFF, 1995)}

Para a construção do icosaedro, são necessários três metros de linha e trinta pedaços de canudos de mesmo comprimento. Construa quatro triângulos (Figura 9), seguindo o esquema da $a$ e os una, obtendo uma pirâmide regular de base pentagonal como a desenhada em $b$. Repita essa construção, que resultará em mais uma pirâmide. Una cada uma das pirâmides por meio dos vérti- 
ces das bases, utilizando pedaços de canudos, de tal forma que em cada vértice se encontrem cinco canudos (figura 9).

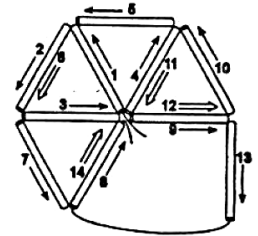

(a)

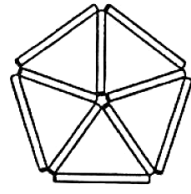

(b)

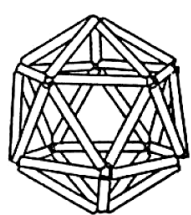

(c)
Figura 9: Esquema de montagem do icosaedro regular Fonte: Kaleff, 1995.

Obs.: No esquema da figura a, indicamos por $\rightarrow$ o sentido em que a linha deve ser inserida num canudo vazio e por $\Longrightarrow$ o sentido em que ela deve ser inserida num canudo já ocupado por algum pedaço de linha.

Se considerarmos agora seis triângulos eqüiláteros, veremos que não é possível formar um ângulo poliédrico, pois, nesse caso, a soma dos ângulos internos dos polígonos em torno do ponto que constituiria o vértice totaliza $360^{\circ}$; consequentemente, ao juntarmos os polígonos, obteremos um ângulo plano de $360^{\circ}$, e não um ângulo poliédrico.

Dessa maneira, cada poliedro regular pode ter, no máximo, cinco triângulos equiláteros em torno de cada vértice. Assim, obtêm-se os poliedros regulares: tetraedro, octaedro e icosaedro.

\section{Atividade II: Quadrados}

Consideremos, agora, poliedros regulares cujas faces são quadrados.

Analogamente ao caso dos triângulos eqüiláteros, não é possível formar um ângulo poliédrico com quatro quadrados:

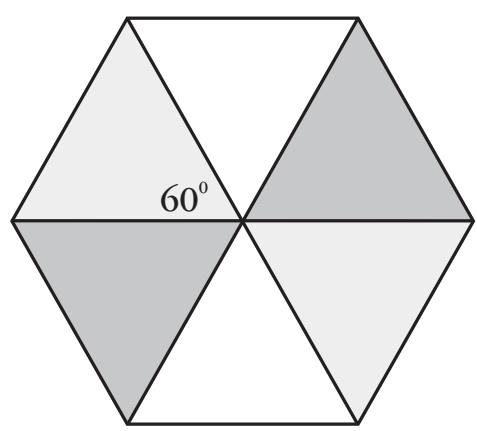

Figura 10: Seis triângulos eqüiláteros em torno do mesmo vértice

Fonte: A autora.

Assim, um poliedro regular cujas faces são quadrados pode ter, no máximo, três quadrados em cada vértice.

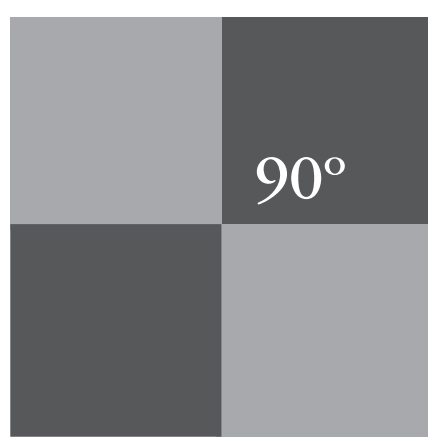

Figura 11: Quatro quadrados em torno do mesmo vértice

Fonte: A autora.

Retirando-se um quadrado dos quatro da figura anterior e juntando-se os pontos A e B, forma-se um vértice do poliedro regular e, completando da mesma forma os outros vértices, obtém-se o poliedro regular de seis faces: o "hexaedro regular", mais conhecido por "cubo".

Esse é o único poliedro regular que tem quadrados como faces. Agora, podemos propor outras atividades de construção de um cubo: 


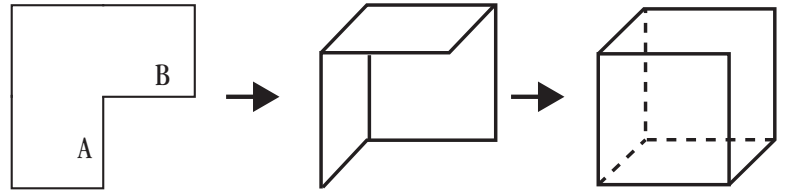

Figura 12: 0 cubo

Fonte: A autora.

\subsection{Montando um cubo a partir de quebra-cabeças (0'DAFFER; CLEMENS, 1976)}

a) Desenhe e recorte, em uma cartolina, três planificações (Figura 13). Construa os sólidos e junte-os para formar um cubo.

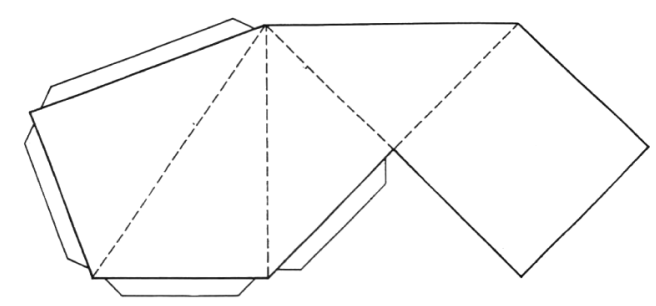

Figura 13: Planificação para a montagem do cubo Fonte: O’Daffer; Clemens, 1976, p. 126.

b) Desenhe e recorte, em uma cartolina, duas planificações Figura 14. Construa os sólidos e junte-os para formar um cubo.

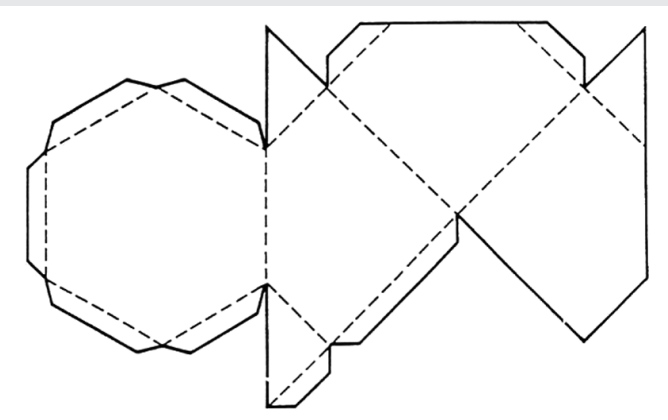

Figura 14: Planificação para a montagem do cubo Fonte: O’Daffer; Clemens, 1976, p. 126.
A atividade anterior permite a exploração dos planos de corte de um cubo, ou seja, possibilita que o aluno responda a questões do tipo: "Como podemos cortar um cubo para obter três pirâmides congruentes?" ou "Como podemos cortar um cubo para obter um hexágono regular?" Dessa forma, manipulando, experimentando, argumentando, os alunos são levados naturalmente à concepção.

\section{Atividade III: Pentágonos regulares}

Agora é a vez de considerar poliedros regulares, cujas faces são pentágonos regulares.

Não se pode cobrir uma região do plano com pentágonos regulares, porque três deles em torno de um ponto deixam um espaço (Figura 15 à esquerda) e, se colocarmos quatro ao redor de um ponto, há uma sobreposição como está mostrado na Figura 15. O professor, da mesma forma que foi feito nas atividades anteriores, pode pedir para que os alunos construam com régua e compasso pentágonos regulares em uma cartolina, recortemnos e faça as experiências.
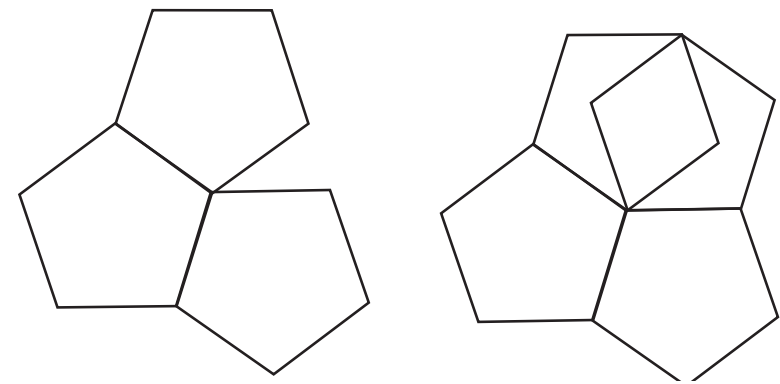

Figura 15: Pentágonos regulares em torno do mesmo vértice

Fonte: A autora.

Com três pentágonos, entretanto, um ângulo poliédrico pode ser formado. Completando, 
da mesma forma, cada um dos outros vértices obtêm-se o poliedro regular de doze faces: o "dodecaedro regular".
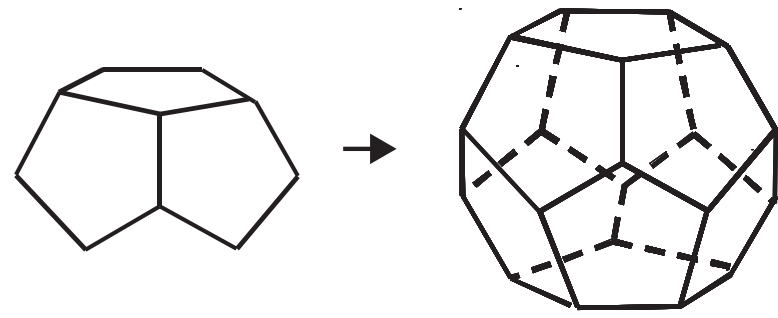

Figura 16: 0 dodecaedro regular

Fonte: A autora.

Esse é o único poliedro regular que tem pentágonos regulares como faces. Agora, podem-se propor outras atividades de construção desse sólido:

\section{III.1 Construindo um dodecaedro regular (O'DAFFER; CLEMENS, 1976).}

a) Desenhe e recorte, em uma folha de papel cartão duas planificações, como sugerido na Figura 17;

b) Dobre ao longo dos lados do pentágono ABCDE;

c) Coloque uma planificação por cima da outra, uma rotacionando $36^{\circ}$, e entrelace um elástico alternadamente por cima e por baixo dos cantos;

d) Levante sua mão e observe o dodecaedro que se formou.

\section{Atividade IV: Outros polígonos regulares}

Peça agora que os alunos tentem colocar três hexágonos em torno de um ponto. Novamente, não teremos nenhum ângulo poliédrico formado e, portanto, nenhum poliedro pode ser feito. As

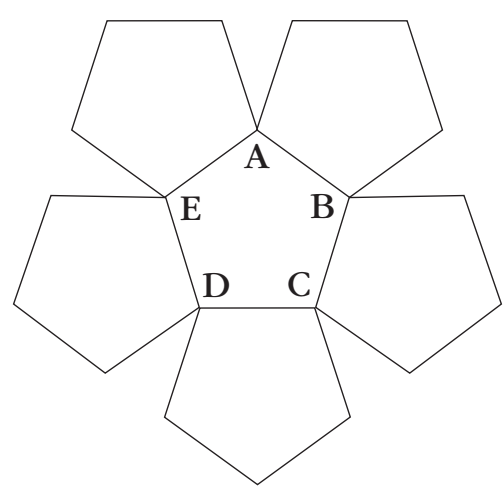

Figura 17: Planificação para a montagem do dodecaedro regular

Fonte: O’Daffer; Clemens, 1976, p. 124..

medidas dos ângulos internos dos heptágonos regulares, octógonos regulares etc. são ainda maiores do que as do hexágono. Assim, ao colocarmos três (ou mais) de cada um desses polígonos regulares ao redor de um ponto, sempre haverá sobreposição:
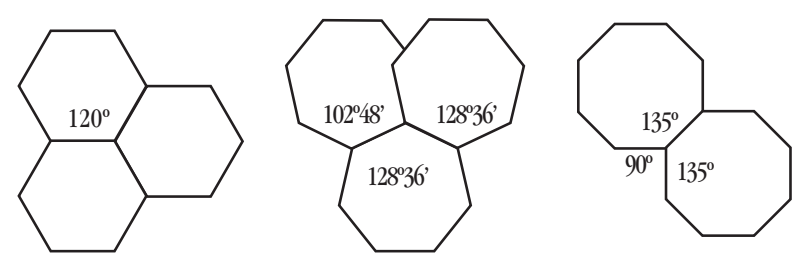

Figura 18: Hexágonos, heptágonos e octógonos regulares em torno do mesmo vértice

Fonte: A autora.

Dessa forma, concluímos que, na tentativa de construir poliedros regulares, verifica-se, intuitivamente, que não é possível fazê-lo nem com hexágonos, nem com polígonos que tenham mais do que seis lados. Enfim, só é possível construir "cinco" tipos de poliedros regulares:

- de três modos distintos, utilizando triângulos (tetraedro, octaedro, icosaedro); 
- de um só modo, utilizando quadrados (hexaedro ou cubo);

- de um só modo, utilizando pentágonos (dodecaedro).

Por meio dessas explorações, o professor pode propor outras atividades, tais como trabalhar as planificações dos cinco sólidos; pedir que os alunos contem o número de arestas (A), de vértices (V) e de faces (F) de cada um dos poliedros regulares e completem uma tabela. Dessa maneira, serão incentivados a encontrar a relação existente entre $\mathrm{V}+\mathrm{F}$ e $\mathrm{A}$, ou seja, a "Fórmula de Euler". Tendo em mãos o octaedro regular construído na atividade 1.3 e quatro tetraedros regulares, como o que foi construído na atividade 1.2, pedir que os estudantes construam outro tetraedro regular, podendo-se explorar a questão: "Como podemos obter um octaedro regular a partir de um tetraedro regular?"

Atividades desse tipo possibilitam ao aluno transitar entre a percepção, a construção, a representação e a concepção de forma natural, cabendo ao professor buscar meios que concretizem tal tarefa.

\section{Considerações finais}

Coerente com a teoria defendida por Machado (1990, 2002) que, conforme vimos, garante que, no processo de construção do conhecimento geométrico em qualquer nível do ensino, em vez de uma polarização percepção/concepção, é fundamental que quatro aspectos sejam articulados no trabalho: a percepção, a construção, a representação e a concepção, este artigo envolveu a proposta de algumas atividades de ensino elabora- das com a preocupação de englobar e articular os processos descritos e necessários para a construção do conhecimento geométrico, além de apresentar as indicações estabelecidas na proposta curricular vigente, ou seja, nos PCNs.

Atualmente, é possível verificar que os livros didáticos, de forma geral, distribuem a geometria no decorrer de toda a edição - e entre as décadas de 1960 e 1990 abordaram a geometria nos capítulos finais, o que fez que, muitas vezes, ela fosse relegada a segundo plano (PAVANELLO, 1989) -, articulando os quatro processos de construção do conhecimento geométrico.

Dessa forma, espera-se que os alunos, formados atualmente com o uso desses livros, apresentem uma melhor compreensão da geometria quando chegarem ao ensino superior daqui a alguns anos. Entretanto, isso não depende apenas dos livros didáticos, mas também e, principalmente, das concepções que os professores apresentam sobre a geometria e o seu ensino, e de suas práticas em sala de aula. Cabe ao professor desenvolver a geometria, evitando o tratamento isolado de qualquer um dos quatro processos necessários na construção do conhecimento geométrico.

Pelo que foi exposto aqui, o trabalho em geometria, em qualquer nível escolar, deve ser organizado em atividades que possibilitem a articulação e o trânsito entre percepção, construção, representação e concepção.

\section{Discussing the Geometry teaching: a proposal for regular polyhedron teaching}

In Geometry classes, in general, there is no articulation between the processes related to perception with those ones that the theorists name concep- 
tion. In this work, we consider that are very important, in all levels of education, the articulation between the perception and the conception and, together with it, between two other dimensions of the dynamics of the process of construction of the geometric knowledge - the construction and the representation. The first one concerns to the elaboration of materials in physical way, and the second one, to reproduction, by drawing, of perceived or constructed objects. Starting from this theoretical framework, we propose a set of activities with the subject "regular polyhedron", to be applied in classroom. These activities were elaborated in accordance with the PCNs (National Curriculum Parameters), which establish the articulation between perception, construction, representation and conception.

Key words: Geometry teaching. Proposal of pedagogical action. Regular polyhedron.

\section{Notas}

1 Este texto é adaptado do primeiro capítulo da dissertação (Mestrado em Educação) intitulado Percepção - Construção - Representação Concepção: os quatro processos do ensino da geometria - uma proposta de articulação, sob a orientação da Profa. Dra. Maria Cristina Bonomi Barufi, defendida em março de 2007, na Faculdade de Educação da Universidade de São Paulo (FE-USP).

\section{Referências}

BRASIL. Secretaria de Educação Fundamental.

Parâmetros Curriculares Nacionais (5 $5^{a}$ $8^{a}$ séries):

Matemática. Brasília, DF: MEC/SEF, 1998.

HILTON, P.; PEDERSEN, J. Build your own Polyhedra. S. 1. Menlo Park, CA: Addison-Wesley, 1988.

KALEFF, A. M. M. R.; REI, D. M. Varetas, canudos, arestas e ... sólidos geométricos. Revista do Professor de Matemática, São Paulo, v. 28, p. 29-36, 1995. ; GARCIA, S. S. Quebra-cabeças

geométricos e formas planas. (Conversando com o professor sobre Geometria - v. 1). Rio de janeiro: EDUFF, 1997.

\section{MACHADO, N. J. Matemática e língua materna} (Análise de uma impregnação mútua). São Paulo: Cortez, 1990.

Epistemologia e didática. As concepções de conhecimento e inteligência e a prática docente. São Paulo: Cortez, 2002.

O'DAFFER; CLEMENS. Geometry: An Investigative Approach. S.l.: Addison-Wesley Publishing Company, 1976.

PAVANELLO, R.M. O abandono do ensino de geometria: uma visão histórica. 1989. 196p. Dissertação (Mestrado em Educação)- Faculdade de Educação, Universidade Estadual de Campinas. Campinas, 1989. recebido em jun. 2008 / aprovado em ago. 2008

Para referenciar este texto:

LAURO, M. M. Discutindo o ensino de geometria: uma proposta para o ensino dos poliedros regulares. Dialogia, São Paulo, v. 7, n. 2, p. 177-188, 2008.

Dialogia, São Paulo, v. 7, n. 2, p. 177-188, 2008. 